\title{
Monitorowanie własnej motywacji w nauczaniu zdalnym
}

\section{KEYWORDS}

monitoring self-motivation, pedagogy of youth and technoculture, media education, postdigital culture, YouTube culture

\begin{abstract}
Kamil Wnuk, Monitorowanie własnej motywacji w nauczaniu zdalnym [Monitoring self-motivation in distance learning]. Kultura - Społeczeństwo - Edukacja nr 2(20) 2021, Poznań 2021, pp. 277-290, Adam Mickiewicz University Press. ISSN 2300-0422, ISSN (Online) 2719-2717. DOI 10.14746/kse.2021.20.17
\end{abstract}

The article discusses new forms of youth self-control in the Internet space, which are actively developing in the postdigital culture. The text analyzes the form of social activism during the coronavirus syndemia, which the author defined as self-motivation monitoring. The use of this cognitive category prompts reflection on specific examples the Internet users, and it allows to capture the self-control mechanism's characteristics of the young generation community on the Internet. The educational discovery of the discussed phenomenon made it possible to notice that there are significant problems in distance learning, and the communities' cooperation in the network is related to the educational process of creating the common good.

Jakże wielu rzeczy w życiu nie dostrzegamy, a tym bardziej w czasie syndemii ${ }^{1}$ koronawirusa, gdy jesteśmy po obu stronach barykady nauczania zdalnego. Obecnie motywacja i wiara $\mathrm{w}$ siebie są dla nas niewidoczne z powodu permanentnej

* ORCID: https://orcid.org/0000-0002-9315-2518.

${ }^{1}$ Syndemia to termin medyczny - zwany jest także synergiczną epidemią, czyli nałożeniem się pandemii COVID-19 na inne współistniejące choroby. W takim ujęciu to powiązanie dwóch lub więcej problemów zdrowotnych, które przyczyniają się do nadmiernego obciążenia chorobami na danej grupie osób w danym miejscu i czasie. 
monotonii, w wyniku której jesteśmy już zmęczeni. Jeśli się nad tym zastanowimy, to nie umiejętności i osobowość, a tylko nasze cele oraz aspiracje sprawiają, że wstajemy rano z łóżka. Natomiast część osób tam zostaje lub przebywa w swoim pokoju (jeśli ma takie warunki) ze względu na stres oksydacyjny będący rezultatem izolacji społecznej (Karpińska, Gromadzka, 2013: 45-53). Niezależnie od tego, czy mamy trzynaście czy trzydzieści lat, czy jesteśmy uczniem, uczennicą lub studentem, studentką, czy nauczycielem, nauczycielką - to nasza motywacja, którą z różnych przyczyn odrzuciliśmy w czasie nauczania zdalnego, spowodowała pewnego rodzaju rozproszenie. Jak więc możemy ją w sobie odnaleźć jako nauczyciele i nauczycielki? Następnie, jak pomóc młodzieży odnaleźć motywację i zachęcać do działań?

Wiemy, że młode pokolenie dosłownie może zmienić świat. Również wiemy, że nauczyciel i nauczycielka $\mathrm{z}$ silną własną motywacją może zainspirować umysły. Natomiast obserwujemy wzrost zainteresowania zjawiskiem współpracy wraz z rozwojem technologii komunikacyjnych (Waytz, Gray, 2018). Znajdujemy się w kapitalizmie inwigilacji (Zuboff 2020), który polega na czerpaniu z obserwacji zachowań ludzi. Praktyka „ery usieciowionego indywidualizmu” (Rainie, Wellman, 2012) w kulturze cyfrowego narcyzmu (Szpunar, 2017) ujawnia szereg działań, które są monitorowane, rejestrowane i tworzą nowe prognozy o tym, co zrobimy oraz kim jesteśmy. Natomiast model biznesowy mediów społecznościowych opiera się na chęci utrzymania ludzi przy ekranach dla najlepszego zwrócenia uwagi. Jak podkreśla Tom G. Stevens - napędza nas do działania społecznie wyuczone pragnienia pieniędzy, miłości, szacunku, osiągnięć, kreatywności, piękna i samorozwoju (Stevens, 2021). Z tego punktu widzenia autor konstatuje: „jak na ironię, wielu ludzi, którzy rozwinęli wysoki stopień samomotywacji, miało rodziców, którzy nie dbali o nich dobrze. Nauczyli się, jak walczyć i pokonywać bariery lub problemy. Nauczyli się pokonywać lęki, podejmować decyzje, planować i ciężko pracować, aby osiągnąć niepewne cele. Nauczyli się, jak dbać o siebie i jak odnosić sukcesy pomimo negatywnych komentarzy lub wpływów innych. Nauczyli się, jak mieć dobrą kontrolę wewnętrzną i umiejętności zarządzania sobą" (Stevens, 2021) w ponowoczesnej rzeczywistości. Przyczyny tych zmian upatrywać można w zrównoważonym rozwoju czy zarządzaniu dobrem wspólnym, budowaniu społeczności produkcji i dóbr cyfrowych z uwzględnieniem nowych modeli konsumpcji i produkcji (Arcidiacono, Gandini, Pais, 2018).

Ogromną rolę we współczesnym świecie odgrywają media, mające szczególny wpływ na kształtowanie postaw dzieci i młodzieży oraz potrzeb racjonalnego korzystania z (nowych-starych) mediów. W takim ujęciu nowe technologie napędzają zmiany we współczesnym społeczeństwie i nie zyskują należytej uwagi w peda- 
gogice. W ujęciu Wielisławy Osmańskiej-Furmanek i Marka Furmanka edukacja medialna jest praktyczną stroną pedagogiki medialnej, kluczem do rozumienia oraz konstruowania znaczeń w rzeczywistości zdominowanej przez kulturę medialną (zdecydowanie przez kulturę postcyfrową ${ }^{2}$ ). W tym kontekście warto wspomnieć, że do głównych zadań edukacji medialnej należy zaliczyć między innymi wskazanie miejsca mediów w kulturze (Osmańska-Furmanek, Furmanek, 2006: 299) postcyfrowej. Internet stał się podwórkiem i fabryką (Scholz, 2012) dla młodych ludzi, gdyż sięga po określone rozwiązania ze sztuki mediów czy z przestrzeni technokultury (Wnuk, 2020: 154). Jak zauważa Krzysztof J. Szmidt, produktem procesu tworzenia jest „nowy sposób komunikacji z innymi, nowa metoda działania, forma zabawy czy sposób postrzegania świata. [...] świadome kształtowanie przez człowieka własnego «ja», rozumienie jako autokreacja lub samorealizacja" (Szmidt, 2005: 80-81). Tymczasem jest to szkielet systemu opartego na wykorzystywaniu nadwyżek dóbr i talentów (Reagle, 2010). Widać więc, że „świat, w którym większość z nas żyje, jest światem, w którym każdy ma jakiś zawód i zajęcie, ma coś do roboty" (Dewey, 1963: 87). Natomiast 48\% dziewczynek w wieku 10-15 lat uznało prowadzenie kanału w mediach społecznościowych takich, jak YouTube, Instagram czy TikTok za atrakcyjne zajęcie zawodowe, w którym widzą siebie w przyszłości ${ }^{3}$. W ten sposób prezentuje się sprawczy charakter działań młodzieży w erze postcyfrowej. Niezbędne jest posiadanie przez jednostki kompetencji, jak: kreatywność, zdolności analityczne (dla monitorowania i wyciągania wniosków) oraz umiejętności testowania rozmaitych rozwiązań dla kontroli. Jak zauważa Michel Foucault: „władza i wiedza wprost się ze sobą wiążą [...] nie ma relacji władzy bez skorelowanego z nimi pola wiedzy, ani też wiedzy, która nie zakłada i nie tworzy relacji władzy" (Foucault, 2009: 29). Warto podkreślić, że wiedza ma charakter społeczny, a każda dyskusja czy spór prowadzi do sytuacji wobec kształtowanych idei, które trudno przypisać konkretnej jednostce (Fleck, 2006: 325). Ludwik Fleck zwraca uwagę, iż pojedynczy, odizolowany człowiek byłby skazany na umysłową bezpłodność (Fleck, 2006: 325-327). Tymczasem składowe takie, jak: dostęp do informacji, wiedza o tym, czego obecnie szukamy, co nas nurtuje w sieci - zajmują wolny czas i przyczyniają się do eksploracji nowych kompetencji czy działań

\footnotetext{
${ }^{2}$ Kultura postcyfrowa - to przestrzeń współistnienia ze sobą elementów kultury analogowej i cyfrowej. Florian Cramer (2014) proponuje alternatywę wobec pary nowe/stare media: to media korporacyjne, mainstreamowe, dominujące i komercyjne oraz media oddolne, alternatywne, o charakterze „zrób to sam”.

${ }^{3}$ Inspiring Girls Polska zleciło agencji badawczej IQS przeprowadzenie badania na temat aspiracji dziewczynek w Polsce. Wykonano je w dniach 2-5 marca 2021 r. metodą CAWI na $N=500$-osobowej reprezentatywnej próbie dziewcząt w wieku 10-15 lat oraz ich matek.
} 
wśród młodzieży. Społeczna dystrybucja wiedzy w tym ujęciu stała się istotnym elementem w przestrzeni Internetu. Posiadaną przez kogoś wiedzę wykorzystuje się w ramach własnych decyzji, która może być uzyskana „wyłącznie w procesie tworzenia planu działań, zdobyta w trakcie pracy nad konkretnym zadaniem, jakiego się podjął w określonych warunkach" (Hayek, 2004: 119).

Warto podkreślić, że współczesne doświadczenia adolescentów w czasie syndemii koronawirusa mogą się przekładać na współpracę z nauczycielem, nauczycielką. Te w połączeniu z mapą motywacyjną opracowaną przez Jamesa Sale’a angażują nasze pragnienia i potrzeby oraz pokazują jak kształtują one to, co robimy i dlaczego to robimy. Faktycznie, te zależności przydają się jeszcze bardziej w obszarach nauczania online z konstruktywistycznym modelem nauczania wobec kultury postcyfrowej (Wnuk, 2020: 152, 156). Życie codzienne młodzieży wpływa na rzeczywistość. Młody człowiek wykonuje działania, nabywa określone przyzwyczajenia, które stają się automatyczne i ,akceptuje u siebie te nawyki tylko dlatego, że ich skutki uważa za korzystne. Jeśli tylko stwierdzi, że postępowanie jest zgodne z nawykami może utrudnić mu osiągnięcie celu uznanego za bardziej pożądany, to zmienia pogląd" (Mises, 2005: 50). Tymczasem młode pokolenie uchyla się od konieczności podejmowania angażujących ich uwagę i energię ciągłych rozstrzygnięć w nauczaniu zdalnym.

\section{Monitorowanie (monitoring)}

W czasach syndemii koronawirusa skupiliśmy się na monitorowaniu czy kontrolowaniu uczniów i uczennic, zapominając, jakie mają potrzeby lub z jakimi problemami się borykają wobec permanentnego strachu (już) o wszystko. Co więcej, to „błąd narzucania celów z zewnątrz jest głęboko zakorzeniony. Nauczyciele otrzymują je od wyższych władz; władze przyjmują z tego, co jest popularne w społeczności. Nauczyciele narzucają je dzieciom" (Dewey, 1963: 119). Szkoła z natury jest polityczna, „zarażająca świat tak bardzo, jak świat go zaraża” (Groys, 2009: 30).

Rozpoczynamy erę gry na czas. Powstają testy z licznikiem upływającego czasu dla każdego zadania. Podczas dziesięciominutowej przerwy między lekcjami online młodzież ma przełączyć się na kolejną lekcję, ewentualnie odpocząć czy iść do toalety lub zrobić sobie herbatę. A gdzie czas na posiłek? Dochodzi jeszcze tłumaczenie, dlaczego spóźnił/spóźniła się na lekcję i wyciąganie od nauczyciela/nauczycielki informacji czy jego/jej obecność została na danej lekcji na pewno odnotowana. Stosowane są wtyczki do przeglądarek umożliwiające automatyczne sprawdzanie, czy uczniowie/uczennice są obecni i kiedy opuścili spotkanie na Google Meet. Meto- 
dy kontroli uczniów/uczennic poprzez korzystanie z kamerek na zajęciach online i metoda zamkniętych oczu podczas odpowiedzi czy skracanie zajęć do trzydziestu minut nie spełniają pierwotnych założeń edukacji, ponieważ młodzież spędza przed ekranami cały dzień. Smartfon stał się naszym pierwszym ekranem i jest nieodzowną częścią codziennego życia. Natomiast liczba użytkowników mediów społecznościowych wzrosła w najszybszym tempie od trzech lat, osiągając poziom 4,20 miliarda (Kemp, 2021). Działania młodzieży są kształtowane w kontekście zastanego społecznego świata na gruncie transcendentalnego indywidualizmu. Struktury świata społecznego i mechanizmy w nim zachodzące są uruchamiane przez praktyki adolescentów poprzez splot działań w sieci także po to, by uwolnić własne innowacje, które z kolei spotykają się z reakcją stabilizującą ze strony rówieśników. Aktywne uczestnictwo jest istotne w zdobywaniu uznania wśród grup rówieśniczych, w zadaniach wymagających współpracy i doświadczenia.

\section{Samokontrola (self-motivation)}

Pojęcie to odnosi się do celowego zwracania uwagi na aspekty zachowania. Jest ważnym składnikiem samoregulowanego uczenia się, które zależy od korzystnej oceny własnych możliwości i postępów w osiąganiu celów edukacyjnych. Syndemia koronawirusa zakłóciła tak edukację, jak i wszelkie aktywności i działania, w których dopatrywaliśmy się swoich szans. W konsekwencji otrzymaliśmy poważny kryzys postrzegania dobrostanu psychicznego, praw i aktywizmu społecznego. Natomiast konflikty w projektach produkcji partnerskiej uzależniają (Reagle, 2010) do aktywniejszego uczestnictwa w przestrzeni Internetu. Obszar nowego doświadczania adolescentów „zawiera się w koncepcji, że istnieje bliska i konieczna relacja pomiędzy procesami rzeczywistego doświadczenia i edukacji” (Dewey, 2014: 34). W rezultacie nowe wyzwania samokontroli ujawniają się z obszaru na brak jasnych motywatorów zewnętrznych. Obecnie najważniejszym czynnikiem wzbudzającym zainteresowanie u młodzieży jest wzbogacenie życia o nowe wartości. W takim ujęciu „czynna kontrola środowiska przez kontrolę organów działania (...) czynna kontrola nad środkami do osiągnięcia celu” (Dewey, 1963: 54) i pozwala zainteresować osoby danym problemem. Czynnikiem wspierającym jest ukazanie rozwoju jako „wzajemnego oddziaływania organizmu ludzkiego i jego środowiska” (Copleston, 2009: 324). Punktem wyjścia dla nauczycieli/ nauczycielek to długofalowe projektowanie treści - motywacji wewnętrznej i zewnętrznej dla ich znaczenia wobec procesu aktywizmu społecznego, internetowego i sieciowego. Głównym celem aktywizmu sieciowego jest zgromadzenie ludzi 
popierających wspólną ideę, obszar czy temat. Beatrice Naujalyte (kanał na YT: The Bliss Bean ${ }^{4}$ ) omawia motywację i samodyscyplinę, a także prezentuje przykłady tego, jak projekt może być zastosowany w codziennym życiu. Z kolei Nasir Kharma, student medycyny (kanał na YT: Kharma Medic ${ }^{5}$ ) wyjaśnia, dlaczego uczy się w 4-godzinnych blokach, natomiast Ali Abdaal (kanał na YT: Ali Abdaal ${ }^{6}$ ) traktuje o pilnej potrzebie radzenia sobie z negatywnym nastrojem czy prokrastynacją. Określona wiedza stanowi tu podstawę do działań podejmowanych przez youtuberów i prowadzi do zmian społecznych w przestrzeni sieci wobec syndemii koronawirusa. W ten sposób można obserwować nowe kierunki, cele, metody czy standardy wobec dociekliwego postępowania młodzieży w Internecie. Natomiast Sheen S. Levine i Michael J. Prietula obserwują, że otwarta współpraca jest przykładem ludzkiej kooperacji, czyli jednostki obce sobie, które wspólnie pracują, aby osiągnąć określone cele (Levine, Prietula, 2014) osiągają sukces. Niemniej, idee współpracy często są przywoływane w perspektywie dzielenia się.

Kultura postcyfrowa i kultura algorytmów zmienia nawyki działania w sieci, a transaktywne doświadczenia pociągną za sobą badania wykraczające poza znane dyscyplinom ograniczenia i konwencje. Dopuszczając eksperyment w transakcjach między dziedzinami wiedzy, przekracza się dychotomie i granice, przekształca zastane pojęcia i problemy (Shusterman, 2015: 180-182). W tym określonym przypadku adolescenci poszerzają czy ulepszają doświadczenia samokontroli w czasach syndemii koronawirusa. Ukierunkowane wobec samego aktu „eksperymentowania, o próbę zbadania, przetestowania i wypróbowania procedur oraz praktyk, a także urządzeń i obiektów, a więc o wyznaczenie zakresu eksperymentów, a nie o ich przewidywalne efekty" (Wachowski, 2020: 74). Następuje transformacja społeczeństwa współpracy na produkcję dóbr i usług. Stanowi to zapowiedź „performatywnych aspektów zmian” (Jemielniak, Przegalińska, 2020: 31).

\section{Monitorowanie własnej motywacji (monitoring self-motivation)}

Młodzież funkcjonuje w mainstreamowej rzeczywistości kultury postcyfrowej na własnych warunkach. $\mathrm{W}$ ten sposób obserwujemy w sieci pozytywne rozwiąza-

\footnotetext{
${ }^{4}$ The Bliss Bean, Motivation vs. Self-Discipline | designing your life, https://www.youtube.com/ watch?v=i9T1os9tiCg, dostęp: 20.04.2021.

${ }^{5}$ Kharma Medic, Dlaczego moge uczyć się 4 godziny BEZ przerw (jak być produktywnym), https://www.youtube.com/watch?v=3NSkk31vFbU, dostęp: 20.04.2021.

${ }^{6}$ Ali Abdaal, How to Stop Procrastinating, https://www.youtube.com/watch?v=yBP1VjO9RSE, dostęp: 20.04.2021.
} 
nia, których dorośli w dużym stopniu nie doceniają. Aby oceniać teraźniejszość, warto także spoglądać w przyszłość. Tymczasem człowiek powinien tworzyć świat dla siebie oraz nadawać mu kształt przez swoje własne określone działania. Tylko w takim świecie możemy znaleźć dla siebie miejsce i realizować swoje życie (Berger, Luckmann, 2021: 85-88). Celowością budowania takiego świata kultury przez człowieka jest zapewniane trwałych struktur, których nie otrzymał biologicznie. Jednak kultura (technokultura) jest zasadniczo odmienna od natury, a człowiek nie tylko stale te struktury tworzy, ale także powinien je odtwarzać. Wynika z tego, że wszystkie struktury kultury w odróżnieniu od porządku natury są nietrwałe i skłonne do zmian (Berger, 1997: 33-34). Możemy obserwować, że wobec części kultury niematerialnej znajduje się społeczeństwo oraz porządek społeczny, w związku z czym pojedynczy i samotny człowiek pozostaje istotą na poziomie zwierzęcym, a rozwój każdej osoby jest poprzedzony przez zastany porządek społeczny (Berger, Luckmann, 2021: 91-93). Sposób użycia przez adolescentów swoich umiejętności, zdolności czy wiedzy i strategii myślenia zależy od tego, w jakim stopniu korzystają z narzędzi technokultury, które zostały im dostarczone w codziennym życiu. Warto podkreślić, że „sposobu życia oraz strategii rozwijania umysłu nie uczymy bez wsparcia, bez rusztowania, nadzy wobec świata" (Bruner, 2006: 133). Uważam, że użycie kamerki na własnych zasadach przez młodzież przy nauczaniu zdalnym jest lepszym rozwiązaniem, niż wymuszanie zachowania monitorowania ucznia czy uczennicy przed kamerką, bo to nie jest motywujące. $\mathrm{Z}$ powodu istniejących w Internecie zagrożeń szczególną uwagę poświęćmy rozwiązaniom projektowania oraz planowaniu przez młode pokolenie rozwiązań innowacyjnych.

Monitorowanie własnej motywacji to zjawisko o charakterze negocjowania postaw własnych, które są zakotwiczone w kulturze cyfrowego narcyzmu. Aczkolwiek ujawnia się nowy typ narcyzmu jako wariant postnarcyzmu z przekonaniem celowości działania ${ }^{7}$. Przyczyn tych zmian możemy upatrywać: (1) w zrównoważonym rozwoju; (2) w zarządzaniu dobrem wspólnym; (3) w budowaniu społeczności i uczestnictwie; (4) w produkcji i dóbr cyfrowych oraz (5) w nowych modelach konsumpcji i produkcji (Arcidiacono, Gandini, Pais, 2018). Istotnym elementem w poszukiwaniu celowości działania są „zasady wzmacniania procesu twórczego"8

\footnotetext{
${ }^{7}$ Autor tekstu opisuje optymistyczny wariant celowości działań w obszarze nauczania zdalnego. Natomiast celowość działań ma charakter osiągnięcia synergii dla kreatywnej współpracy jednostek, czy otwartych i zaangażowanych inicjatyw, które prowadzą do wyszukania nowego rozwiązania w danym problemie młodych ludzi.

${ }^{8}$ Termin „zasada wzmacniania procesu twórczego” zdefiniowany przez Krzysztofa J. Szmidta, który określa zasady pomocy jednostki: (1) zasada facylitacji; (2) zasada kontaktu grupowego; (3) za-
} 
(Szmidt, 2005: 98-108) w koncepcji zasady facylitacji. Funkcja facylitacji (z języka łacińskiego facilis - „łatwy”, z języka francuskiego faciliter - „ułatwiać”) polega na usprawnieniu, ułatwieniu procesu zdobywania wiedzy i opanowaniu umiejętności twórczych. W przestrzeni Internetu następuje rozszerzenie funkcji facylitacji o negocjowanie postaw społecznych. Dostosowane są do tego potrzeby w kierunku stylu życia typu facylitacji i tożsamości typu facylitacji ${ }^{9}$ - jako nowy symbol kolejnych przemian młodych ludzi wobec konsekwencji kultury instant.

Młodzież podjęła inicjatywę, aby wspierać siebie wzajemnie przy jednoznacznym określeniu problemów i wyjaśnieniu bieżącej sytuacji, w jakiej się aktualnie znajduje. Wobec istotnych problemów w nauczaniu zdalnym młode pokolenie wprowadza mainstreamowe użycie kamerki, czyli monitorowanie własnej motywacji (monitoring self-motivation). Mamy do czynienia w tym przypadku z typizacją „świata życia codziennego" i podstawową świadomością pojawiających się zjawisk edukacyjnych w czasach syndemii koronawirusa. Widzimy zatem, iż „szczególną formą doświadczenia, w której myślenie zdroworozsądkowe zapoznaje się ze światem społeczno-kulturowym. Nie ma ono nic wspólnego z introspekcją, lecz stanowi rezultat procesu uczenia się czy też akulturacji (...) w żadnym wypadku nie jest prywatną sprawą obserwatora, która nie mogłaby być kontrolowana przez doświadczenia innych obserwatorów" (Schütz, 2008: 9). Napotkanie różnorodnych, wyjątkowych zdarzeń w sieci ujawnia wiedzę postrutynową składającą się z wiedzy zręcznościowej, która odwołuje się do codziennych praktyk refleksyjnych i wiedzy praktycznej. Jak to ujmuje Aleksander Manterys: „wiedza jednostki o świecie społecznym to podstawowy instrument organizacji doświadczenia (...) jest dostępna potencjalnie wszystkim jednostkom pod postacią społecznego zasobu wiedzy (...) ich orkiestrację łączącą w całość poczynania poszczególnych aktorów" (Manterys, 2008: X). Tymczasem wszystkie te poczynienia możemy zaobserwować w społeczności youtuberów, którzy stali się liderami zmian w sieci, a w konsekwencji influencerami, przy dbaniu o wizerunek własnej osoby i marki. Pojawił się zatem charakterystyczny styl montażu na YouTube, a w ostateczności profesjonalne produkcje wideo. Ajgor Ignacy, jeden z byłych polskich twórców serwisu YouTube, który przedstawił w realizacji filmowej Otwieram kino przepis na elitarną produkcję, informuje dodatkowo, że $80 \%$ treści produkowanych na polskim YouTube to

sada ludyczności; (4) zasada rozwijania autonomicznej motywacji poznawczej; (5) zasada wzmacniania procesu twórczego; (6) zasada przeciwdziałania przeszkodom oraz (7) zasada osobistej twórczości nauczyciela. Prezentowane zasady są rozumowaniem procesu twórczego i motywacji aktywności twórczej w klasie szkolnej z punktu widzenia wychowawczego.

${ }^{9}$ Styl życia typu facylitacji i tożsamość typu facylitacji - wprowadzone przez autora teksu. 
tania rozrywka, kicz i kieruje się tym co modne ${ }^{10}$. Jak zauważają Peter L. Berger i Thomas Luckmann: „motyw użyteczności jest w życiu codziennym motywem wiodącym, szczególne miejsce w społecznym zasobie wiedzy zajmuje «wiedza o charakterze przepisu», to znaczy wiedza ograniczona do znajomości skutecznych sposobów postępowania, ułatwiająca wykonywanie zwykłych czynności” (Berger, Luckmann, 2021: 79). Mamy do czynienia z takim motywem w syndemii koronawirusa, który ułatwi młodzieży dbanie o własne postępowanie wobec odizolowania rówieśniczego. Co jest charakterystyczne dla monitorowania własnej motywacji wobec zamieszczonych materiałów wideo na kanale YouTube? To, że mamy odpowiedni i „ładny” kadr, estetykę przejętą z kultury youtuberskiej oraz ład przy jednoczesnym dbaniu o szczegóły. Ujawnia się celebracja procesu uczenia się i odpowiedniego przygotowania się do jednej-, dwu-, czy pięciogodzinnej sesji (np. Elloitsangela ${ }^{11},{ }^{12}$ Merve $^{13}$, Eucalyptus ${ }^{14}$, Verym $^{15}$, Suzlnne ${ }^{16}$, Kharma Medic ${ }^{17}$, Joonpiter ${ }^{18}$ - uczą się z rówieśnikami). W oczywisty sposób staje się „skuteczniejszym procesem przystosowania do panujących warunków, zaspokajania własnych potrzeb oraz nabywania umiejętności rozwiązywania problemów, jakie pojawiają się przed człowiekiem" (Gałkowski, 2003: 216-217). Młodzież uczy się we względnej ciszy, gdzie występują naturalne, dobiegające z pokoju dźwięki czy odgłosy deszczu, a w warstwie wideo widoczny jest najczęściej licznik odmierzający czas sesji. Pojawiają się także filmy z muzyką relaksacyjną w strukturze wideo. Zauważalny jest również porządek i ład na biurku w określonym kadrze, w celu prezentacji procesu uczenia się we własnym pokoju. Obserwujemy wyłaniającą się społeczność (wspólnotę) odpowiedzialną za proces dzielenia się własnymi wskazówkami

10 Ajgor Ignacy, Otwieram kino, https://www.youtube.com/watch?v=klHwqLtOrQ4, dostęp: 20.04.2021.

11 Elloitsangela, Real time study with me (no music): 2 hour pomodoro session with breaks (background noise), https://www.youtube.com/watch?v=yZDtCrY2CUY, dostęp: 20.04.2021.

12 Elloitsangela, $2 \mathrm{hr}$ real time study with me at home: $30 \mathrm{~min}+8 \mathrm{~min}$ breaks (no music, background noise, timer), https://www.youtube.com/watch?v=8S4GDVF2klk, dostęp: 20.04.2021.

13 Merve, 3 hour study with me | Background noise, Rain Sounds, 10-min break, No Music, https://www.youtube.com/watch?v=1ex_bNIFR1A, dostęp: 20.04.2021.

14 Eucalyptus, (calm piano music, real time) $2 \mathrm{hr}$ sunset study with me, https://www.youtube.com/ watch?v=5m4QcGCBoC0, dostęp: 20.04.2021.

15 Verym, Study with me ft. clouds, white noise, jazz, https://www.youtube.com/watch? $\mathrm{v}=$ ZWOkNE3H4C8, dostęp: 20.04.2021.

16 Suzlnne, Study with me (with classic, real time, study asmr), https://www.youtube.com/ watch?v=4GETLwyeUwU, dostęp: 20.04.2021.

${ }_{17}$ Kharma Medic, Real time study with me (no music): 5 hour Productive Pomodoro Session, https://www.youtube.com/watch?v=qIxx7ffhPy0, dostęp: 20.04.2021.

18 Joonpiter, [bts asmr] study w/ namkook at a chill cafe in seoul [w/ soft bgm from their playlists], https://www.youtube.com/watch?v=UM8eFncgJUI, dostęp: 20.04.2021. 
czy wspierania siebie nawzajem w syndemii koronawirusa. $Z$ tego powodu „wartości tworzone są $\mathrm{w}$ zapośredniczonych spotkaniach relacji kształtowanych przez system społeczny ze światami symbolicznymi, toteż rezultatem owych spotkań jest zróżnicowane wartościowanie konkretnych procesów społecznych" (Alexander, 1987: 308). Co ciekawe, pojawia się strona internetowa dla studentów i studentek StudyStream.live - ucz się z najbardziej produktywna społecznością. Możemy również zaobserwować, że platforma przeznaczona jest dla wszystkich studentów i studentek zarówno na poziomie uniwersyteckim, jak i dla młodzieży szkolnej, „działa na zasadzie spotkań przez platformę Zoom i «widzenia» uczących się z całego świata. Aby uczestniczyć w procesie monitorowania własnej motywacji należy się upewnić, że mamy włączone wideo oraz wyłączony mikrofon. Ten sposób pomógł mi w zmotywowaniu się, dzięki czemu dłużej mogłem być skupiony na nauce"19. Jeśli osoba przestaje koncentrować się na własnej nauce, to społeczność zwróci się w komunikacie na czacie o powrót do inicjatywy uczenia się. Według Jae Kyung Ha i Yong-Hak Kim motywacją do dzielenia się zasobami z innymi jest możliwość przynależności do grupy, poczucia satysfakcji, jakie daje pomaganie, czy przekonanie, że można liczyć na innych (Ha, Kim, 2008), czyli na kolegów i koleżanki. Kluczowym pojęciem w tym zakresie jest interaktywność, performatywność użytkowników/użytkowniczek w kontekście nowoczesnych technologii. Nie tylko używają jej dla swojej korzyści, ale także są wystawiani na jej bezpośredni wpływ i modyfikują własne zachowania oraz procesy poznawcze, dostosowane do obecnej sytuacji (Prósinowski, Krzywdziński, 2018: 25). Przenikanie się rzeczywistości wirtualnej i realnej w czasie syndemii dobitnie prezentuje „real” (Korab, 2013: 141), w którym doświadczenia dostarczane są przez urządzenia techniczne. Człowiek, który wszedł w kontakt z realem, spogląda na rzeczywistość w nowy czy zmodyfikowany sposób. Młodzi ludzie, dzieląc się swoimi zasobami, spowodowali podtrzymywanie relacji poprzez sam akt dzielenia się w edukacji zdalnej. Celem było utrzymanie relacji na własnych i określonych zasadach, aby monitorować własną motywację. Pewną innowacją był fakt, że monitorowanie niejako żyje własnym życiem w przestrzeni sieci. Młodzież w sposób świadomy i z wolnością bytu cyfrowego ujawniła nowe zjawisko dzielenia się w sposób zauważalny w znacznej części własnego życia. Podstawowym kontekstem obcowania jest przestrzeń realu, w której obecnie dostrzegamy siatkę poznawczą i interakcyjną dla aktywności adolescentów. Wobec ekspresji w kulturze postcyfrowej oraz codzienności w syndemii koronawirusa „część historii ludzkiej ekspresji da się ująć właśnie jako

${ }^{19}$ Jan Grussy, uczeń kl. 2 z VI Liceum Ogólnokształcącego im. Ignacego Jana Paderewskiego w Poznaniu. 
pasmo poszukiwań nowego sposobu na doskonalszą przestrzenną transgresję, na jak najlepsze wejście poza «tu i teraz» - pragnienie to jest stale obecnym elementem kultury (...) i udostępniane przez nie cyfrowe światy są zatem naturalną konsekwencją tej tendencji, następna forma transgresyjnych poszukiwań” (Kubiński, 2016: 48). Takim doznaniem mogą być aktywności facylitowania, które stanowią nieprzeliczoną rzeszę samodzielnych i niezależnych programów komputerowych towarzyszących nam na co dzień (Prósinowski, Krzywdziński, 2018: 30). Działanie to może nabrać głębszego znaczenia, jeśli odniesiemy je do form sztuki, która w tym wypadku mogłaby okazać się wejściem w interaktywną, intymną relację z wytworem sztuki bądź wkraczania na „scenę teatralną” we własnym pokoju $\mathrm{w}$ celu nie tylko odegrania roli, lecz wchodzenia $\mathrm{w}$ interakcję $\mathrm{z}$ rówieśnikami i rówieśniczkami, stwarzania historii czy wykorzystywania motywacji do swoistej transgresji poszukiwania bliskości (Kozielecki, 2002; Chmielińska, 2017). Ten wymiar wirtualny w czasie syndemii to poszukiwanie nowych historii i wyobrażeń uczenia się, które oddziałują na decyzje oraz codzienność młodzieży.

\section{Konkluzja}

Nasze życie nie toczy się obok mediów, lecz żyjemy w mediach na własnych warunkach, które określają obecny sposób życia i pracy ze względu na mainstreamową rzeczywistość kultury postcyfrowej. Warto zauważyć, że w chwili obecnej „nie zdobywamy wiedzy, stojąc na zewnątrz świata; wiemy, ponieważ znajdujemy się wewnątrz niego" (Barad, 2012: 358). Natomiast w przestrzeni młodych ludzi Internet jest centralną osią wiedzy. Co ważne, syndemia koronawirusa ujawniła u adolescentów zmianę w postrzeganiu struktury „Ja” w mediach społecznościowych. Potrzebujemy więc refleksji w pedagogice i edukacji medialnej (ze sztuką mediów ${ }^{20}$ ), alternatywnego realizmu, który uświadomi nam zachodzące interferencje między nami a młodym pokoleniem w nauczaniu zdalnym, a także w kulturze postcyfrowej. Jak zauważa Marcin Składanek - jesteśmy skazani na „poruszanie się w obrębie skomplikowanej, pełnej pułapek i paradoksów przestrzeni wyznaczonej przez porządki symboliczne, modele teoretyczne, operacyjne reguły, interfejsy czy technologie innowacyjne” (Składanek, 2017: 186). Mamy obowiązek wykorzystywać narzędzia cyfrowe do stymulowania myślenia krytycznego i innowacyjnego, a także zmiany w sferze zawodowej, wiedzy i kontroli. Według Philipa

${ }^{20}$ Wobec medialnego świata hybryd i hybrydyzacji oraz zagadnień technokultury sugeruję poszerzenie przedmiotu badań i praktyki edukacji medialnej o obszar sztuki mediów oraz kultury postcyfrowej. 
Balla istotnym elementem kontroli i współczesnej komunikacji są sposoby zarządzania niewidocznych zasobów energii (Ball, 2019: VI) jako technologii interwencyjnej na własnych zasadach. Dlatego należy zgodzić się z Douglasem Rushoffem, który uważa, że technologie cyfrowe to system ukierunkowany na określony cel, a „ludzie, którzy je programują, odgrywają coraz ważniejszą rolę w kształtowaniu naszego świata i jego funkcjonowania. Poza tym, to same technologie cyfrowe będą kształtować nasz świat, zarówno przy naszej wyraźnej współpracy, jak i bez niej" (Rushkoff, 2010: 8). Młodzież w przestrzeni sieci wprowadziła samo-śledzenie (self-tracking ${ }^{21}$ ), aby dokonać zapisu technologicznego własnego zdrowia, kondycji i samopoczucia (Twardoch-Raś, 2021: 514). Ujawnia się w tym zakresie kluczowe obszary dla pedagogiki (również medialnej), które warunkują zachowania młodzieży w monitorowaniu własnej motywacji do „odpowiedniego zoptymalizowania życia" ${ }^{22}$ wobec ustanowionych norm dla zdrowia jednostki w kulturze postcyfrowej. Na tej podstawie obserwujemy konstruującą się kulturę postnarcy$\mathrm{zmu}^{23}$, która $\mathrm{w}$ świecie ponowoczesnym potrzebuje „etosu zdrowia” i ponownego zdefiniowania zmian w strukturze „Ja" wśród młodzieży.

\section{Bibliografia}

Alexander J.C. (1987), Action and Its Environments, [w:] J.C. Alexander, B. Giesen, R. Münch, N.J. Smelser (red.), The Micro-Macro Link, Berkeley, s. 289-318.

Arcidiacono D., Gandini A., Pais I. (2018), Sharing what? The 'sharing economy' in the sociological debate, https://journals.sagepub.com/doi/abs/10.1177/0038026118758529, dostęp: 22.10.2021.

Ball P. (2019), Foreword, [w:] A. Grønstad, Ø. Vågnes (red.), Invisibility in Visual and Material Culture, Cham, s. V-X.

Barad K. (2012), Posthumanistyczna performatywność: ku rozumieniu, jak materia zaczyna mieć znaczenie, tłum. J. Bednarek, [w:] A. Gajewska (red.), Teorie wywrotne. Antropologia przekładów, Poznań, s. 323-362.

${ }^{21}$ Określany przez Ginę Neff i Dawn Nafus (2016: 1-3) jako zespół ludzkich aktywności, polegających na rejestrowaniu i analizie danych pozyskiwanych z własnych ciał. Personalne praktyki przeradzają się w zjawiska kolektywne, które przyczyniają się do współczesnych zmian społecznych od potrzeb jednostek i koncentrują się na zarządzaniu populacją.

${ }^{22}$ Określenie wprowadziła Ewelina Twardoch-Raś (2021: 525), która wskazuje, że praktyki samo-śledzenia kształtują współczesne możliwości życia jako: „etos zdrowia”, „wola zdrowia”, „parametryzowanie siebie”, „technologia siebie”, czy „dyscyplinowanie” wokół społeczności Quantified-Self (wprowadzona w roku 2008 przez Gary'ego Wolfa i Kevina Kelly’ego). Idea Quantified-Self opiera się na wykorzystywaniu wiedzy o nas samych, jaką możemy czerpać z analizy własnych danych.

${ }^{23}$ Określenie wprowadzone przez autora tekstu. Kultura postnarcyzmu w ujęciu kultury postcyfrowej określa funkcjonowanie bez podziału na online i offline wobec tego, że młodzież funkcjonuje w życiu codziennym jednocześnie w obydwu przestrzeniach. W obliczu takich zmian dostrzegamy między innymi nowe zjawiska, jak monitorowanie własnej motywacji. 
Berger P.L. (1997), Święty baldachim, Kraków.

Berger P.L., Luckmann T. (2021), Społeczne tworzenie rzeczywistości, Warszawa.

Bruner J.S. (2006), Kultura edukacji, Kraków.

Chmielińska A. (2017), Dynamika transgresji twórczych. Studia przypadków pedagogów, Łódź.

Copleston F. (2009), Historia filozofii. Od Benthama do Russella, t. 8, tłum. B. Chwedeńczuk, Warszawa.

Cramer F. (2014), What Is 'Post-digital'?, APRJA, 3(1), s. 10-24, https://aprja.net//article/view/116068, dostęp: 16.04.2021.

Dewey J. (1963), Demokracja i wychowanie. Wstęp do filozofii wychowania, tłum. Z. Bastgen, Warszawa.

Dewey J. (2014), Doświadczenie i edukacja, tłum. E. Czujko-Moszyk, Warszawa.

Fleck L. (2006), Kryzys w nauce. Ku nauce wolnej i bardziej ludzkiej, tłum. W. Sady, [w:] L. Fleck, Z. Cackowski, S. Symotiuk, Psychosocjologia poznania naukowego: Powstanie i rozwój faktu naukowego oraz inne pisma z filozofii poznania, Lublin, s. 324-329.

Ford M. (2017), Świt robotów. Czy sztuczna inteligencja pozbawi nas pracy?, Warszawa.

Foucault M. (2009), Nadzorować i karać. Narodziny więzienia, tłum. T. Komendant, Warszawa.

Gałkowski S. (2003), Rozwój i odpowiedzialność. Antropologiczne podstawy koncepcji wychowania moralnego, Lublin.

Groys B. (2009), Education by Infection, [w:] S.H. Madoff (red.), Art School (Propositions for the $21^{\text {st }}$ Century), London s. 25-36.

Ha J.K., Kim Y.-H. (2008), An Exploration on On-line Mass Collaboration: focusing on its motivation structure, http://citeseerx.ist.psu.edu/viewdoc/download;jsessionid=478C9CF5089AD915 1A7D11E04F379A3F?doi=10.1.1.306.4848\&rep=rep1\&type=pdf, dostęp: 16.04.2021.

Hayek F.A. von (2004), Zgubna pycha rozumu. O błędach socjalizmu, tłum. M. i T. Kunińscy, Kraków.

Jemielniak D., Przegalińska A. (2020), Społeczeństwo współpracy, Warszawa.

Karpińska A., Gromadzka G. (2013), Stres oksydacyjny i naturalne mechanizmy antyoksydacyjne znaczenie w procesie neurodegeneracji. Od mechanizmów molekularnych do strategii terapeutycznych, Postępy Higieny i Medycyny Doświadczalnej, 67, s. 43-53.

Kemp S. (2021), Digital 2021. Raport, https://wearesocial.com/digital-2021, dostęp: 20.04.2021.

Korab K. (2010), Filozofia i socjologia wirtualnej rzeczywistości, [w:] K. Korab (red.), Wirtual. Czy nowy wspaniały świat?, Warszawa, s. 11-43.

Kozielecki J. (2002), Transgresja i kultura, Warszawa.

Kubiński P. (2016), Gry wideo. Zarys poetyki, Kraków.

Levine S.S., Prietula M.J. (2014), Open Collaboration for Innovation: Principles and Performance, https://www.researchgate.net/publication/263545221_Open_Collaboration_for_Innovation_ Principles_and_Performance, dostęp: 22.10.2021.

Manterys A. (2008), Działanie i sprawczość w socjologii Schütza, [w:] A. Schütz, O wielości światów. Szkice z socjologii fenomenologicznej, tłum. B. Jabłońska, Kraków, s. VII-XVIII.

Mises L. von (2005), Theory and History: An Interpretation of Social and Economic Evolution, Indianapolis.

Neff G., Nafus D. (2016), Self-Tracking, Cambridge-London.

Osmańska-Furmanek W., Furmanek M. (2006), Pedagogika mediów, [w:] B. Śliwerski (red.), Pedagogika. Podręcznik akademicki, t. 3: Subdyscypliny wiedzy pedagogicznej, Gdańsk, s. 295-312.

Prósinowski P., Krzywdziński P. (2018), Cyfrowa miłość. Romanse w grach wideo, Kraków.

Rainie L., Wellman B. (2012), Networked: The New Social Operating System, Cambridge. 
Reagle J.M. (2010), "Be Nice”: Wikipedia norms for supportive communication, https://www.researchgate.net/publication/220590153_Be_Nice_Wikipedia_norms_for_supportive_communication, dostęp: 22.10.2021.

Rushkoff D. (2010), Program or Be Programmed: Ten Commands for a Digital Age, New York.

Scholz T. (2012), Digital Labor: The Internet as Playground and Factory, New York.

Schütz A. (2008), O wielości światów. Szkice z socjologii fenomenologicznej, tłum. B. Jabłońska, Kraków.

Shusterman R. (2015), Transactional Experiential Inquiry: From Pragmatism to Somaesthetics, Contemporary Pragmatism, vol. 12, s. 180-195.

Składanek M. (2017), Sztuka generatywna. Metoda i praktyki, Łódź.

Stevens T.G. (2021), Self-Motivation and Self-Control. Learn How to Motivate Yourself and Control Your Own Thoughts, Behavior, and Emotions, https://web.csulb.edu/ tstevens/self-motivation. htm, dostęp: 24.04.2021.

Szmidt K.J. (2005), Współczesne koncepcje wychowania do kreatywności i nauczania twórczości: przegląd stanowisk polskich, [w:] K.J. Szmidt (red.), Dydaktyka twórczości. Koncepcje - problemy rozwiązania, Kraków, s. 19-133.

Szpunar M. (2017), Kultura cyfrowego narcyzmu, Kraków.

Twardoch-Raś E. (2021), Sztuka biometryczna w perspektywie filozofii post- $i$ transhumanizmu. W stronę estetyki postafektywnej, Kraków.

Wachowski J. (2020), Transakty. Między sztuką, nauka i technologia. Nowe strategie performowania wiedzy, Kraków.

Waytz A., Gray K. (2018), Does Online Technology Make Us More or Less Sociable? A Preliminary Review and Call for Research, https://www.researchgate.net/publication/321106387_Does_Online_Technology_Make_Us_More_or_Less_Sociable_A_Preliminary_Review_and_Call_for_ Research, dostęp: 22.10.2021.

Wnuk K. (2020), Esej trickstera i edukatora edukacji kulturowej, [w:] A. Cybal-Michalska, A. Gromkowska-Melosik (red.), Młodzi naukowcy na uniwersytecie. Pomiędzy teoria a praktyka edukacyjna, Poznań, s. 143-160.

Zuboff S. (2020), Wiek kapitalizmu inwigilacji. Walka o przyszłość ludzkości na nowej granicy władzy, tłum. A. Unterschuetz, Poznań. 